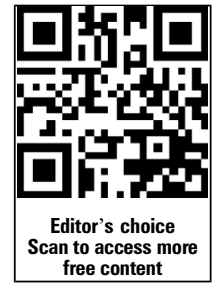

free content

Cardiology Department, AP-HP, Bichat University Hospital, Paris, France

\section{Correspondence to} Professor Bernard lung, Cardiology Department, AP-HP Bichat Hospital, 46 rue Henri Huchard, Paris 75018, France; bernard.iung@bch.aphp.fr

Received 8 March 2013 Accepted 8 April 2013 Published Online First 27 April 2013

\section{SLinked}

- http://dx.doi.org/10.1136/ heartjnl-2013-304135

To cite: Bouleti $C$, lung $B$, Himbert $D$, et al. Heart 2013;99:1336-1341.

\title{
Long-term efficacy of percutaneous mitral commissurotomy for restenosis after previous mitral commissurotomy
}

\author{
Claire Bouleti, Bernard lung, Dominique Himbert, Eric Brochet, David Messika-Zeitoun, \\ Delphine Détaint, Eric Garbarz, Bertrand Cormier, Alec Vahanian
}

\section{ABSTRACT}

Objective We analysed long-term results of percutaneous mitral commissurotomy (PMC) performed because of mitral restenosis after previous commissurotomy.

Design Follow-up of a prospective cohort.

Setting Tertiary university hospital.

Patients We studied 163 consecutive patients who underwent PMC because of restenosis occurring 16 \pm 8 years after previous commissurotomy (closed-heart in 121, open-heart in 30 and PMC in 12). Mean age was $48 \pm 14$ years; 62 patients (38\%) had valve calcification. Restenosis was due to bicommissural fusion in all cases. Intervention PMC using a single or double balloon in 80 patients and the Inoue balloon in 83 .

Results Good immediate results (IR) (valve area $\geq 1.5 \mathrm{~cm}^{2}$ with $M R \leq 2 / 4$ ) were obtained in $135 \mathrm{pts}$ (83\%). 20 -year rates were $27.9 \pm 4.7 \%$ for cardiovascular survival without mitral surgery and $14.8 \pm 3.9 \%$ for good functional results (cardiovascular survival without reintervention on the mitral valve and in New York Heart Association (NYHA) class I or II). After good IR, 20-year rates were $33.2 \pm 5.5 \%$ for cardiovascular survival without surgery and $17.9 \pm 4.7 \%$ for good functional results. After good IR, multivariate predictive factors of poor late functional results were higher NYHA class $(p=0.01)$, atrial fibrillation $(p=0.0002)$ and higher mean mitral gradient after PMC ( $p=0.004)$.

Conclusions In patients with restenosis after mitral commissurotomy, PMC provides good IR in most cases. After good $I R$, one patient out of three remains free from surgery and one out of five has good functional results at 20 years. These findings support the use of PMC after previous commissurotomy, particularly in selected patients with few symptoms and in sinus rhythm.

\section{INTRODUCTION}

Mitral commissurotomy, whether surgical of percutaneous, is hampered by late mitral restenosis, which is a frequent presentation of mitral stenosis in Western countries, given the decrease of new cases of rheumatic valve disease. ${ }^{1}$ Surgery of mitral restenosis is most often a mitral valve replacement with the long-term risk of prosthesis-related complications. Since previous commissurotomy is often a surgical commissurotomy (closed- or open-heart commissurotomy), patients are also exposed to the risk of redo mitral surgery and are thus considered to be at a higher risk for surgery. Percutaneous mitral commissurotomy (PMC) can be used to treat restenosis, but only a few series reported mid-term results, the longest follow-up being 10 years. ${ }^{2-10}$ In addition, a history of commissurotomy has been identified as a predictive factor of poor immediate and late results in certain series of PMC. ${ }^{11}{ }^{12}$ Series with long-term follow-up are therefore needed to evaluate the usefulness of PMC in deferring surgery in patients with previous commissurotomy.

The aim of this study is to assess the very longterm results from repeat PMC for restenosis after previous commissurotomy in terms of survival, freedom from mitral surgery, freedom from any mitral intervention and good late functional results. We also analysed the predictive factors of immediate and late results to better select candidates to the procedure.

\section{METHODS}

\section{Study population}

Between 1986 and 1995, 163 consecutive patients residing in France underwent PMC because of restenosis after a previous commissurotomy in our institution. These 163 patients represent $16 \%$ of the 1024 procedures of PMC performed in our institution during this period. Closed-heart commissurotomy was performed in 121 patients, open-heart commissurotomy in 30 patients and PMC in 12 patients. All patients had experienced functional improvement after initial commissurotomy. PMC was performed a mean of $16 \pm 8$ years after previous commissurotomy (up to 38 years). Baseline characteristics of the population are reported in table 1 . Mean age was $48 \pm 14$ years $(23-80) ; 140$ patients $(86 \%)$ were highly symptomatic in New York Heart Association (NYHA) class III or IV.

\section{Measurements}

Echocardiographic examination was performed on the day preceding PMC and 24-48 h after the procedure by the same experienced examiners. The reference measurement for valve area was planimetry by two-dimensional echocardiography on the short axis view. In cases of missing data, Doppler was used as a substitution measurement. ${ }^{11}$ The severity of mitral regurgitation was assessed according to Sellers' classification on left ventriculography in a $30^{\circ}$ right anterior oblique view. In cases of missing data, we used an assessment by colour Doppler. ${ }^{13}$

After echocardiography and fluoroscopy, valve anatomy was classified into three groups according 
Table 1 Baseline characteristics of the population of 163 patients

\begin{tabular}{lc}
\hline Variables & Mean \pm SD or $\mathbf{n}(\%)$ \\
\hline Age (years) & $48 \pm 14$ \\
Female sex & $137(84)$ \\
NYHA functional class & \\
I & $0(0)$ \\
II & $23(14)$ \\
III & $131(80)$ \\
IV & $9(6)$ \\
Atrial fibrillation & $77(47)$ \\
Previous embolic events & $13(8)$ \\
Left atrium diameter & $51 \pm 9$ \\
Mitral regurgitation & \\
0 & $103(63)$ \\
1 & $58(36)$ \\
2 & $2(1)$ \\
Valve anatomy (Cormier's score) & \\
1 & $5(3)$ \\
2 & $96(59)$ \\
3 & $62(38)$ \\
Valve area (echocardiography), $\mathrm{cm}^{2}$ & $1.1 \pm 0.2$ \\
Mean gradient (Doppler), mm Hg & $10 \pm 5$ \\
\hline NYHA,New York Heart Association. &
\end{tabular}

to Cormier's score as previously reported: flexible valves and mild subvalvular disease (chordae $\geq 10 \mathrm{~mm}$ long) (group 1), flexible valves and extensive subvalvular disease (chordae $<10 \mathrm{~mm}$ long) (group 2), and calcified valves confirmed by fluoroscopy (group 3). ${ }^{11} 14$

In addition, we systematically assessed the commissural status using echocardiography on the parasternal short axis view. We considered PMC only if the restenosis was the consequence of refusion of both commissures. ${ }^{3}$ In case of persistent opening of one or both commissures, restenosis was presumed to be mainly the consequence of valvular and/or subvalvular rigidity, and surgery was considered the best option if its risk was not estimated to be prohibitive.

Good immediate results were defined as a composite criterion of final valve area $\geq 1.5 \mathrm{~cm}^{2}$ and mitral regurgitation $\leq 2 / 4$.

\section{Procedure}

All the procedures were performed using the antegrade transvenous approach. A single balloon was used in the first four patients, then a double balloon in 76. Finally, beginning in October 1990, we systematically used the Inoue balloon in the remaining 83 patients according to the stepwise technique under echocardiographic monitoring.

\section{Follow-up}

Follow-up was performed prospectively in the 163 patients residing in France who underwent PMC for mitral restenosis after previous commissurotomy. Data were collected either during patient's visits to the department or by a standardised questionnaire sent to the patient's cardiologist.

Follow-up was concluded in December 2008. Follow-up was considered incomplete if the last follow-up contact was before January 2008.

The events taken into account for the follow-up were death, need for reintervention on the mitral valve and NYHA class III or IV at last follow-up. These clinical events were combined in the following composite endpoints:

- overall survival

- cardiovascular survival without reintervention on the mitral valve (surgery or repeat PMC)

- cardiovascular survival without mitral surgery

- good functional results defined as cardiovascular survival without reintervention on the mitral valve and in NYHA class $\leq$ II.

\section{Statistical analysis}

All data were entered prospectively in a computerised database starting from 1986.

Continuous variables were expressed as mean value \pm SD. Cumulative survival curves were determined by the KaplanMeier method. Univariate analysis of the predictive factors of poor immediate results was performed using a paired $t$ test for continuous variables and a $\chi^{2}$ test for qualitative variables. Variables with $\mathrm{p}<0.25$ were entered in a multivariate logistic model and selected by a backward procedure with a threshold of $p=0.05$. Univariate analysis of the predictive factors of late results was performed using a log rank test. The dependent variable was the previously defined composite endpoint of good functional results. Independent variables with $\mathrm{p}<0.25$ were entered in a multivariate Cox proportional hazards model and were selected by a backward procedure with a threshold of $\mathrm{p}=0.05$. Analysis was performed with SAS statistical software (release 9.2, SAS Institute Inc. SAS Institute, Cary, North Carolina, USA).

\section{RESULTS}

\section{Immediate results}

Of the 163 patients who underwent PMC, there was no procedural mortality but one patient experienced embolism with sequelae. The most frequent complication was traumatic mitral valve regurgitation in nine patients (5\%). Good immediate results were obtained in 135 patients (83\%). There was no significant difference in the rates of good immediate results according to the type of initial commissurotomy: $68 \%$ after closed-heart commissurotomy, $77 \%$ after open-heart commissurotomy and 68\% after PMC $(\mathrm{p}=0.61)$. The two predictive factors of poor immediate results in multivariate analysis were older age (adjusted OR per 10-year increase: $1.97,95 \%$ CI 1.42 to $2.73, \mathrm{p}<0.0001$ ) and smaller valve area (adjusted OR per $0.1 \mathrm{~cm}^{2}$ decrease $1.35,95 \%$ CI 1.09 to $1.67, \mathrm{p}=0.006$ ).

Poor immediate results were related to insufficient valve opening in 19 patients $(12 \%)$ and to mitral regurgitation $\geq$ Seller's grade 3 in nine patients $(5 \%)$.

After PMC, valve area increased from $1.1 \pm 0.2$ to $1.8 \pm 0.3 \mathrm{~cm}^{2}$ $(\mathrm{p}<0.0001)$ and mean gradient decreased from $10 \pm 5$ to 5 $\pm 2 \mathrm{~mm} \mathrm{Hg}(\mathrm{p}<0.0001)$.

\section{LATE RESULTS}

Follow-up was completed for 151 patients (93\%) with a median follow-up period of 89 months (IQR 33-171). The first events which occurred during follow-up are detailed in table 2.

Death occurred in 31 patients and was from cardiovascular cause in $48 \%$ of them.

The most frequent events were interventions on the mitral valve in 91 patients. Surgical management was required in 67 patients (74\%), and consisted most often in mitral valve replacement. A repeat PMC was performed in 24 patients $(26 \%)$, a mean of $10 \pm 5$ years after the index PMC. Finally, 10 patients were in NYHA class III or IV at last follow-up, either waiting 
Table 2 Events occurring during follow-up

\begin{tabular}{|c|c|c|c|}
\hline Events & $\begin{array}{l}\text { Whole population } \\
(n=163) \\
n(\%)\end{array}$ & $\begin{array}{l}\text { Good immediate } \\
\text { results }(n=135) \\
n(\%)\end{array}$ & $\begin{array}{l}\text { Poor immediate } \\
\text { results }(n=28) \\
n(\%)\end{array}$ \\
\hline Death & $31(19)$ & $23(17)$ & $8(29)$ \\
\hline Cardiovascular & $15(9)$ & 8 (6) & $7(25)$ \\
\hline Non-cardiovascular & $16(10)$ & $15(11)$ & $1(4)$ \\
\hline $\begin{array}{l}\text { Procedure on } \\
\text { mitral valve }\end{array}$ & $91(56)$ & $72(53)$ & $19(68)$ \\
\hline Repeat PMC & $24(15)$ & $24(18)$ & 0 \\
\hline $\begin{array}{l}\text { Conservative } \\
\text { surgery }\end{array}$ & $5(3)$ & $4(3)$ & 1 (4) \\
\hline $\begin{array}{l}\text { Isolated mitral } \\
\text { valve replacement }\end{array}$ & $54(33)$ & $36(26)$ & $18(64)$ \\
\hline $\begin{array}{l}\text { Mitral valve } \\
\text { replacement+other } \\
\text { procedure }\end{array}$ & $8(5)$ & $8(6)$ & 0 \\
\hline $\begin{array}{l}\text { NYHA class III or } \\
\text { IV (non-operated) }\end{array}$ & $10(6)$ & $8(6)$ & $2(7)$ \\
\hline
\end{tabular}

for surgery or under medical treatment alone because of surgical contra-indication or patient's wishes.

Overall 20-year survival was $67.9 \pm 5.6 \%$ in the whole population and $72.4 \pm 5.7 \%$ after good immediate results.

The curves corresponding to the composite endpoints (cardiovascular survival without reintervention, cardiovascular survival without surgery and good functional results) are represented in figures 1-3 for the whole population of 163 patients and for the patients who experienced good and poor immediate results (135 and 28 patients, respectively).

Cardiovascular survival without mitral surgery was 27.9 $\pm 4.7 \%$ at 20 -year follow-up for the whole population. After good immediate results of PMC, it was $72.4 \pm 4.3 \%$ at 10 years and $33.2 \pm 6.3 \%$ at 20 years (figure 1 ).

Cardiovascular survival without reintervention on the mitral valve was $16.2 \pm 4.3 \%$ at 20 -year follow-up for the whole population. After good immediate results of PMC, the rate of cardiovascular survival without reintervention was $60.8 \pm 4.6 \%$ at 10 years and $19.1 \pm 5.0 \%$ at 20 years (figure 2 ).

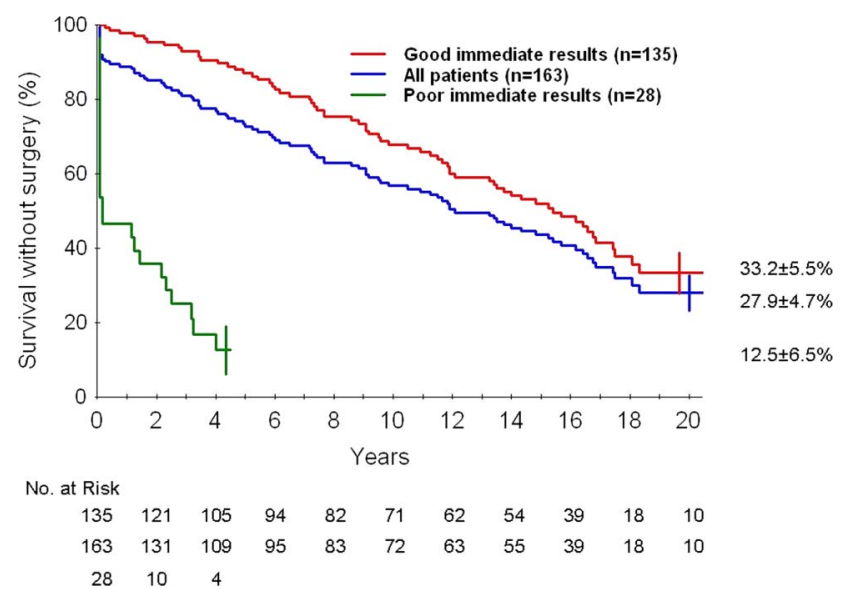

Figure 1 Cardiovascular survival without surgery at 20-year follow-up after percutaneous mitral commissurotomy for mitral restenosis following previous commissurotomy in the whole population and in patients who experienced good and poor immediate results. KaplanMeier rates are presented with SEs.

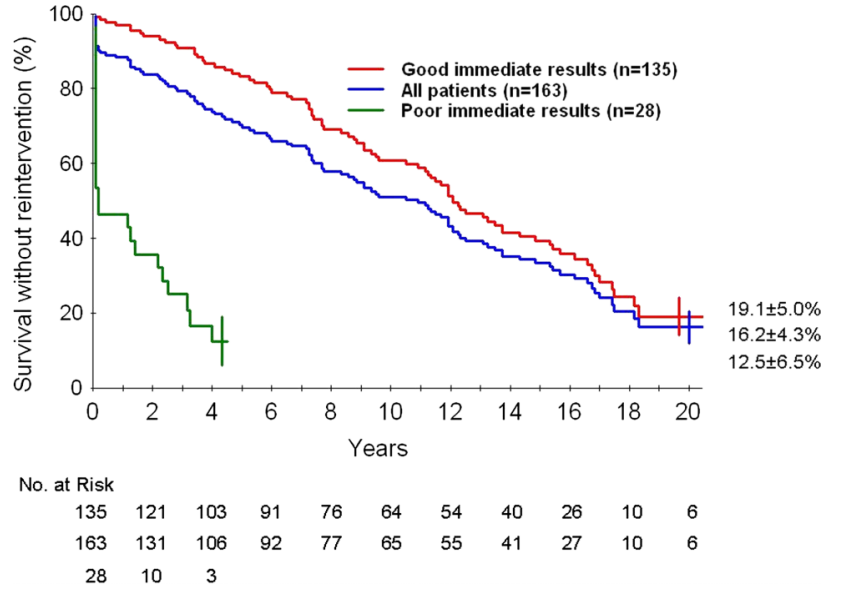

Figure 2 Cardiovascular survival without reintervention at 20-year follow-up after percutaneous mitral commissurotomy for mitral restenosis following previous commissurotomy in the whole population and in patients who experienced good and poor immediate results. Kaplan-Meier rates are presented with SEs.

Good functional results, defined as cardiovascular survival without reintervention on the mitral valve and in NYHA class I or II, were $14.8 \pm 3.9 \%$ at 20 -year follow-up in the whole population. After good immediate results of PMC, the rate of good functional results was $57.7 \pm 4.5 \%$ at 10 years and $17.9 \pm 4.7 \%$ at 20 years (figure 3 ).

There were no differences in terms of 10 -year good functional results according to the type of previous commissurotomy $(49 \pm 5 \%$ and $40 \pm 9 \%$ for initial closed- and open-heart commissurotomy, respectively, and $49 \pm 15 \%$ for initial PMC, $\mathrm{p}=0.67$ ) (figure 4).

The univariate analysis of the predictive factors of late functional results in the 135 patients who underwent good immediate results of PMC is presented in table 3.

The multivariate Cox analysis identified three predictive factors of poor late functional results after good immediate results of PMC (table 4). Two predictors were preprocedural variables, that is, a higher NYHA functional class $(p=0.01)$ and

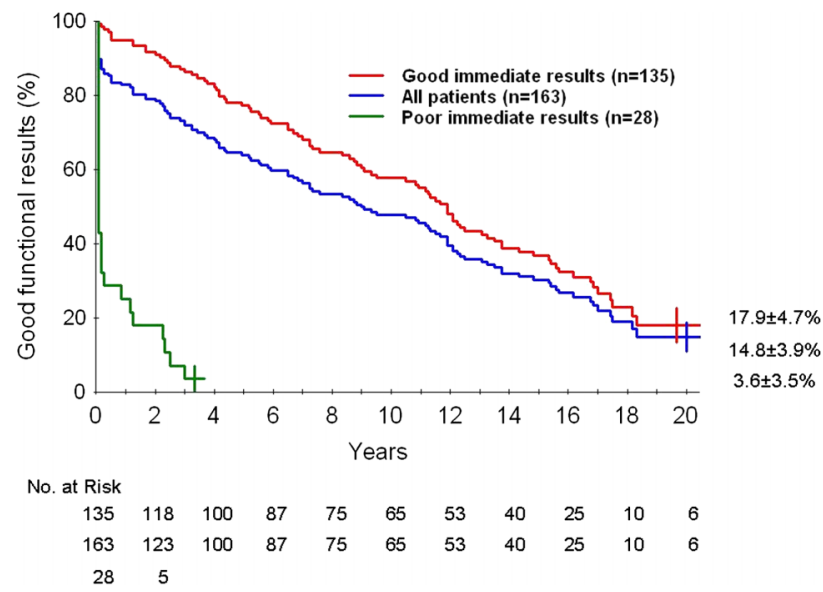

Figure 3 Twenty-year actuarial rates of good functional results after percutaneous mitral commissurotomy for mitral restenosis following previous commissurotomy in the whole population and in patients who experienced good and poor immediate results. Kaplan-Meier rates are presented with SEs. 


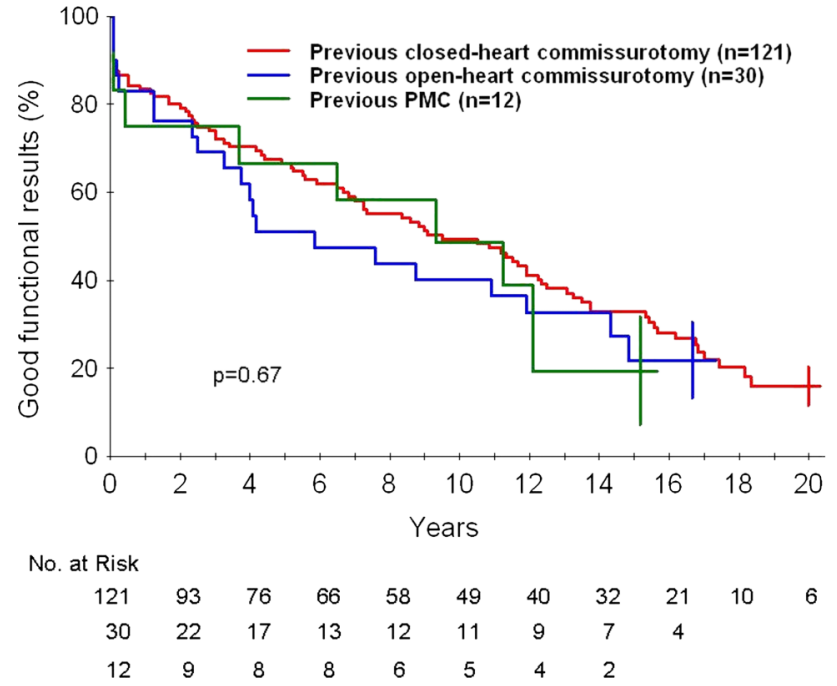

Figure 4 Twenty-year actuarial rates of good functional results after percutaneous mitral commissurotomy (PMC) for mitral restenosis according to the type of prior commissurotomy in the whole population. Kaplan-Meier rates are presented with SEs.

initial atrial fibrillation $(p=0.0002)$. The third predictive factor was a higher mean mitral gradient after PMC $(\mathrm{p}=0.004)$.

\section{DISCUSSION}

In this series reporting the longest follow-up of PMC for restenosis after initial mitral commissurotomy, PMC provided good immediate results in the majority of cases (83\%). After good immediate results, more than half of patients remained free from reintervention after 10 years and almost one out of five patients still presented with good functional results at 20 years. We also specifically studied the issue of survival without surgery which has never been studied in this particular population. After good immediate results of PMC, one out of three patients was free from surgery at 20-year follow-up. These results lead to strongly considering PMC in this population, in particular in patients with moderate symptoms and in sinus rhythm.

\section{Population}

In this series, previous mitral commissurotomy consisted in closed-heart in the majority of patients (74\%), followed by open-heart (17.5\%) and PMC (7.5\%). Besides the usual contraindications for PMC, only patients with mitral restenosis due to bicommissural refusion were candidates for PMC, as now recommended. ${ }^{15}$ Restenosis with persistent commissural opening is due to valve rigidity and PMC should not be attempted in these cases.

The only series reporting a follow-up beyond 15 years included a small number of patients with previous commissurotomy, precluding any analysis of this subgroup. ${ }^{16} 17$ The interest of the present series is to specifically assess the very long-term follow-up of this particular population, presenting with less favourable characteristics. This is attested by the fact that $86 \%$ of patients were highly symptomatic in NYHA class III or IV, almost half of patients (47\%) had initial atrial fibrillation and only $3 \%$ of our population presented with ideal anatomical conditions.

It is therefore of particular interest to assess the impact of PMC following previous commissurotomy in this population since surgical management would consist most often of mitral
Table 3 Univariate analysis of the predictive factors of late functional results after good immediate results of PMC

\begin{tabular}{|c|c|c|}
\hline Variables and subgroups & HR $(95 \% \mathrm{Cl})$ & $p$ Value \\
\hline \multicolumn{3}{|l|}{ Preprocedural variables } \\
\hline Age (per 10-year increase) & $1.15(0.94$ to 1.40$)$ & 0.17 \\
\hline Male sex & $1.29(0.75$ to 2.22$)$ & 0.36 \\
\hline NYHA functional class & & 0.08 \\
\hline Per one class increase & $1.72(0.94$ to 3.13$)$ & \\
\hline Valve anatomy & & 0.14 \\
\hline 1 & 1 & \\
\hline 2 & $1.35(0.91$ to 2.00$)$ & \\
\hline 3 & $1.82(0.82$ to 4.01$)$ & \\
\hline Rhythm & & 0.001 \\
\hline Sinus & 1 & \\
\hline Atrial fibrillation & $2.16(1.40$ to 3.35$)$ & \\
\hline Previous commissurotomy & & 0.85 \\
\hline Closed-heart & 1 & \\
\hline Open-heart & $1.12(0.64$ to 1.98$)$ & \\
\hline PMC & $1.20(0.65$ to 2.62$)$ & \\
\hline Valve area, $\mathrm{cm}^{2}$ & & 0.83 \\
\hline Per $0.1 \mathrm{~cm}^{2}$ decrease & $0.99(0.89$ to 1.10$)$ & \\
\hline Mean gradient, mm Hg & & 0.62 \\
\hline Per one $\mathrm{mm} \mathrm{Hg}$ increase & $0.99(0.94$ to 1.04$)$ & \\
\hline Mitral regurgitation & & 0.07 \\
\hline 0 & 1 & \\
\hline $1-2$ & $1.48(0.96$ to 2.28$)$ & \\
\hline \multicolumn{3}{|l|}{ Per-procedural variables } \\
\hline Type of balloon & & 0.97 \\
\hline Single or double balloon & 1 & \\
\hline Inoue & $1.01(0.66$ to 1.55$)$ & \\
\hline \multicolumn{3}{|l|}{ Postprocedural variables } \\
\hline Valve area, $\mathrm{cm}^{2}$ & & 0.07 \\
\hline Per $0.1 \mathrm{~cm}^{2}$ decrease & $1.09(0.99$ to 1.19$)$ & \\
\hline Mean gradient, mm Hg & & 0.02 \\
\hline Per one $\mathrm{mm} \mathrm{Hg}$ increase & 1.15 (1.02 to 1.30$)$ & \\
\hline Mitral regurgitation & & 0.71 \\
\hline $0-1$ & 1 & \\
\hline 2 & $0.95(0.73$ to 1.24$)$ & \\
\hline
\end{tabular}

valve replacement with the inherent operative risks of redo surgery and of long-term prosthesis-related complications. ${ }^{18} 19$

\section{Immediate results}

In this series, there was neither procedural mortality nor tamponade, showing the safety of the procedure. Good immediate results were obtained in $83 \%$ of patients showing the efficacy of the procedure even in this population with less favourable anatomical and clinical characteristics. There was no significant difference regarding good immediate results according to the type of initial commissurotomy (closed- or open-heart commissurotomy and PMC). Older age and smaller valve area were the two independent factors associated with poor immediate results. This is consistent with predictive factors identified in a large series of PMC. ${ }^{112021}$ The impact of age has been shown to be particularly marked in patients with a history of commissurotomy. ${ }^{11}$

\section{Long-term results}

In this series of 163 consecutive patients with previous commissurotomy (surgical commissurotomy in the majority), overall 
Table 4 Multivariate Cox analysis of the predictive factors of poor late functional results after good immediate results of PMC

\begin{tabular}{llc}
\hline Variables and subgroups & HR $(95 \% \mathrm{Cl})$ & $\mathbf{p}$ Value \\
\hline $\begin{array}{l}\text { NYHA functional class } \\
\quad \text { Per one class increase }\end{array}$ & $1.97(1.12$ to 3.45$)$ & 0.02 \\
$\begin{array}{l}\text { Rhythm } \\
\quad \text { Sinus }\end{array}$ & 1 & 0.0002 \\
$\quad$ Atrial fibrillation & $2.32(1.40$ to 3.60$)$ & 0.004 \\
Mean gradient after PMC & \\
$\quad$ Per 1 mm Hg increase & $1.19(1.06$ to 1.35$)$ & \\
\hline NYHA,New York Heart Association; PMC, percutaneous mitral commissurotomy.
\end{tabular}

survival was $68 \%$ at 20 years after PMC. This illustrates the low mortality rate of treated mitral stenosis even in this population with less favourable characteristics.

At 20 years, a large majority of patients had a reintervention on the mitral valve since only $16 \%$ of patients were free from any reintervention. Reinterventions consisted most often in mitral surgery and when surgery was performed, it was a mitral valve replacement in the majority of cases $(68 \%$ of reinterventions). Only a few conservative surgeries were possible given the anatomy of the mitral valve and the majority were performed in the group of good immediate results. It is interesting to note that in this group (135 patients) a third of the reinterventions consisted in a new PMC, again deferring the time for surgery. Therefore, $28 \%$ of patients were free from surgery at 20 years, this rate increasing to $33 \%$ after good immediate results of PMC. The unique long-term follow-up reported in this series allows us to accurately assess the role of PMC in postponing surgery, which has never been analysed in previous series of PMC for restenosis, all of which considered all types of reintervention (surgery and re-PMC) together.

Good functional results after good immediate results were obtained in $58 \%$ of patients at 10 years and only $18 \%$ of patients at 20 years. Even though 20 year results are less good than usual in reported series after PMC, we must take into account the characteristics of this particular population, with non-favourable anatomy and frequent non-favourable clinical characteristics. Moreover, in this study the linear shape of the different event free survival curves shows that deterioration of the results of PMC is progressive over time. There is indeed no drop of the curves and no cut-off point in terms of years of follow-up beyond which results dramatically fall. We can thus expect that a close follow-up would allow patients to be referred for timely surgery when needed.

Even if most patients present with non-ideal anatomical conditions, these results show that PMC should be considered for mitral restenosis due to refusion of both commissures after previous commissurotomy in two different types of populations:

- the very high surgical risk patients, in which it is a valuable palliative procedure

- good candidates for PMC, with favourable clinical conditions as assessed by the identification of predictive factors of good immediate and late results, that is, younger and less symptomatic patients in sinus rhythm.

For patients with non-favourable clinical conditions, PMC may be considered according to the individualised expected risk of mitral surgery.

The only postprocedural variable predicting late functional results was mitral gradient. The prognostic role of mitral gradient has been shown in other studies and in our overall experience. $^{22-25}$ Mitral gradient should therefore be taken into account in the analysis of immediate results of PMC and for planning follow-up.

\section{Study limitations}

A limitation of the present study is the absence of standardised echocardiographic follow-up. We could, therefore, neither analyse the anatomical mechanisms involved in secondary deterioration after successful PMC nor establish the exact rate of mitral restenosis.

We report no difference in terms of immediate or long-term results according to the type of initial commissurotomy (closedor open-heart surgical commissurotomy or PMC). The limited number of subjects of the three subgroups may, however, be insufficient to provide sufficient statistical power.

\section{CONCLUSIONS}

This series shows that in selected patients with restenosis after previous commissurotomy, successful PMC enables one out of three patients to remain free from any other surgery at 20 years. After good immediate results of PMC, one out of five patients still exhibits good functional results at 20 years, even though almost no patients presented with favourable anatomical characteristics. These findings support the use of PMC after previous commissurotomy in selected cases, particularly in patients with few symptoms and in sinus rhythm.

Contributors CB participated in data collection and analysis and drafted the manuscript. $\mathrm{BI}$ and $\mathrm{AV}$ designed the study, analysed and interpreted the data, and revised critically the manuscript content. $D H, D M-Z, E B, D D, E G$ and $B C$ were in charge of the haemodynamic and echocardiographic data collection, analysis and interpretation, and revised the manuscript. All authors approved the final version of the submitted manuscript.

Competing interests Dr lung has received consultant fees from Servier, Boehringer Ingelheim, Bayer, Valtech and Abbott, and speaker's fees from Edwards Lifesciences, St. Jude Medical and Sanofi-Aventis. Dr Himbert has received proctoring fees from Edwards Lifesciences and Medtronic. Dr Brochet received proctoring fees from Edwards Lifesciences. Dr Messika-Zeitoun has received speaker's fees from Edwards Lifesciences. Dr Vahanian is a member of Advisory Board for Medtronic, Abbott, Valtech, and has received speaker's fees from Edwards Lifesciences and Siemens. The other authors report no conflict of interests.

Ethics approval This study consisted of only a follow-up after usual care and was not a clinical trial.

Provenance and peer review Not commissioned; externally peer reviewed.

\section{REFERENCES}

1 lung B, Baron G, Tornos P, et al. Valvular heart disease in the community: a European experience. Curr Probl Cardiol 2007;32:609-61.

2 Jang IK, Block PC, Newell JB, et al. Percutaneous mitral balloon valvotomy for recurrent mitral stenosis after surgical commissurotomy. Am J Cardiol 1995:75:601-5

3 lung B, Garbarz E, Michaud P, et al. Percutaneous mitral commissurotomy for restenosis after surgical commissurotomy: late efficacy and implications for patient selection. J Am Coll Cardiol 2000;35:1295-302.

4 Fawzy ME, Hassan W, Shoukri M, et al. Immediate and long-term results of mitral balloon valvotomy for restenosis following previous surgical or balloon mitral commissurotomy. Am J Cardiol 2005;96:971-5

5 Davidson CJ, Bashore TM, Mickel M, et al. Balloon mitral commissurotomy after previous surgical commissurotomy. The National Heart, Lung, and Blood Institute Balloon Valvuloplasty Registry participants. Circulation 1992;86:91-9.

6 Medina A, Suarez De Lezo J, Hernandez E, et al. Balloon valvuloplasty for mitral restenosis after previous surgery: a comparative study. Am Heart $J$ 1990;120:568-71.

7 Serra A, Bonan R, Lefevre $T$, et al. Balloon mitral commissurotomy for mitral restenosis after surgical commissurotomy. Am J Cardiol 1993;71:1311-15.

8 Sharma S, Loya YS, Desai DM, et al. Balloon valvotomy for mitral restenosis after open or closed surgical commissurotomy. Int J Cardiol 1993:39:103-8. 
9 Lau KW, Ding ZP, Gao W, et al. Percutaneous balloon mitral valvuloplasty in patients with mitral restenosis after previous surgical commissurotomy. A matched comparative study. Eur Heart J 1996;17:1367-72.

10 Gupta S, Vora A, Lokhandwalla Y, et al. Percutaneous balloon mitral valvotomy in mitral restenosis. Eur Heart J 1996;17:1560-4.

11 lung B, Cormier B, Ducimetiere $\mathrm{P}$, et al. Immediate results of percutaneous mitral commissurotomy. A predictive model on a series of 1514 patients. Circulation 1996:94:2124-30.

12 Palacios IF, Sanchez PL, Harrell LC, et al. Which patients benefit from percutaneous mitral balloon valvuloplasty? Prevalvuloplasty and postvalvuloplasty variables that predict long-term outcome. Circulation 2002;105:1465-71.

13 Helmcke F, Nanda NC, Hsiung MC, et al. Color Doppler assessment of mitral regurgitation with orthogonal planes. Circulation 1987;75:175-83.

14 Cormier B, Vahanian A, Michel PL, et al. (Evaluation by two-dimensional and doppler echocardiography of the results of percutaneous mitral valvuloplasty). Arch Mal Coeur Vaiss 1989;82:185-91.

15 Vahanian A, Alfieri O, Andreotti $F$, et al. Guidelines on the management of valvular heart disease (version 2012): The joint task force on the Management of Valvular Heart Disease of the European Society of Cardiology (ESC) and the European Association for Cardio-Thoracic Surgery (EACTS). Eur Heart J 2012;33:2451-96.

16 Fawzy ME, Fadel B, Al-Sergani $\mathrm{H}$, et al. Long-term results (up to 16.5 years) of mitral balloon valvuloplasty in a series of 518 patients and predictors of long-term outcome. J Interv Cardiol 2007;20:66-72.

17 Fawzy ME. Long-term results up to 19 years of mitral balloon valvuloplasty. Asian Cardiovasc Thorac Ann 2009;17:627-33.
18 Hammermeister K, Sethi GK, Henderson WG, et al. Outcomes 15 years after valve replacement with a mechanical versus a bioprosthetic valve: final report of the Veterans Affairs randomized trial. J Am Coll Cardiol 2000:36:1152-8.

19 Oxenham H, Bloomfield P, Wheatley DJ, et al. Twenty year comparison of a Bjork-Shiley mechanical heart valve with porcine bioprostheses. Heart 2003;89:715-21.

20 Multicenter experience with balloon mitral commissurotomy. NHLBI Balloon Valvuloplasty Registry Report on immediate and 30-day follow-up results. The national heart, lung, and blood institute balloon valvuloplasty registry participants. Circulation 1992:85:448-61.

21 Cruz-Gonzalez I, Sanchez-Ledesma M, Sanchez PL, et al. Predicting success and long-term outcomes of percutaneous mitral valvuloplasty: a multifactorial score. Am J Med 2009;122:581 e11-19.

22 Meneveau N, Schiele F, Seronde MF, et al. Predictors of event-free survival after percutaneous mitral commissurotomy. Heart 1998;80:359-64.

23 Ben-Farhat $\mathrm{M}$, Betbout $\mathrm{F}$, Gamra $\mathrm{H}$, et al. Predictors of long-term event-free survival and of freedom from restenosis after percutaneous balloon mitral commissurotomy. Am Heart J 2001;142:1072-9.

24 Wang A, Krasuski RA, Warner JJ, et al. Serial echocardiographic evaluation of restenosis after successful percutaneous mitral commissurotomy. J Am Coll Cardiol 2002;39:328-34.

25 Bouleti C, lung B, Laouenan C, et al. Late results of percutaneous mitral commissurotomy up to 20 years: development and validation of a risk score predicting late functional results from a series of 912 patients. Circulation 2012;125:2119-27. 